\title{
Proton Pump Inhibitors and Clopidogrel: What are the Clinically Important Interactions between Them?
} \author{
Rahman $^{2}$ and Kais Albalbissi ${ }^{2}$ \\ ${ }^{1}$ Department of Surgery, FMH College of Medicine \& Dentistry, Pakistan \\ ${ }^{2}$ Department of Internal Medicine, East Tennessee State University, USA
}

Ahsan Zil E Ali ${ }^{1}$, Ghulam Murtaza ${ }^{2 *}$, Mohsen Pourmorteza ${ }^{2}$, Ahmed M Al-Sheyyab ${ }^{2}$, Nicolas Mungo ${ }^{2,}$ Zia

Submission: July 10, 2017; Published: August 04, 2017

*Corresponding author: Ghulam Murtaza, Department of Internal Medicine, East Tennessee State University, 325 N. State of Franklin Road, Johnson City, TN, USA, Tel: 4237411863; Email: murtazag@etsu.edu

\begin{abstract}
Background: Antiplatelet therapy is the hallmark therapy for patients with coronary artery disease status post percutaneous coronary intervention (PCI) with stenting. Millions of patients are subjected to such intervention and therapy annually. However recently, attention has been raised against the use of PPIs regarding its potential to decrease the efficacy of clopidogrel. Even the U.S. Food and Drug Administration (FDA) has issued warnings regarding the related use of these medications.

Objective: We have evaluated multiple studies in an effort to shed light into the ambiguity of concomitant use of PPIs and clopidogrel in relation to increase risk for myocardial infarction (MI).

Method: A web-based literature search was conducted through PubMed and Scholar using the keywords "proton pump inhibitors," "Myocardial infarction," and "clopidogrel." Of the available results, 78 relevant studies were reviewed and summarized.

Conclusion: After evaluating the 78 relevant studies, we conclude that there is significant lack of evidence regarding drug-drug interaction between PPIs and clopidogrel. Several studies have shown that PPIs alter the inhibitory effect of clopidogrel, but are deemed to be of low quality and increased bias. For this reason, a randomized clinical trial is pivotal to help resolve the controversy of concomitant use of PPIs and clopidogrel in relation to increase risk for Myocardial infarction. For clinicians with concerns of such interaction we recommend an alternative option like $\mathrm{H}_{2}$-receptor antagonists or maintaining a time gap between the administration of PPI and clopidogrel.
\end{abstract}

Keywords: Proton pump inhibitors; Myocardial infarction; Clopidogrel

\section{Introduction}

The $\mathrm{H}^{+} / \mathrm{K}^{+}$ATPase physiology of the gastric tissue was known in 1970 s, since then a counter regimen was under preparation against acidic environment of stomach [1]. Initially, timiprazole was considered due to its anti-secretory activity but later, by optimization, omeprazole was accepted as the final product for medical use [2]. The groups of these anti-secretory compounds are popularly known as Proton Pump Inhibitors (PPIs). They soon became one of the top prescribed over-the-counter drugs worldwide. Most of the PPIs are the derivatives of benzimidazole although the newer principal compound, imidazopyridine is more promising and may replace the current widely prescribed PPIs [3].

Proton pump inhibitors are commonly prescribed for gastro esophageal reflux disease (GERD), a disease that is rapidly increasing worldwide. Although the prevalence on geographic distribution is quite variable, North America stands uppermost on the utilization list with $18.1 \%-27.8 \%$ and East Asia lowest with less than $10 \%$ [4]. A probable explanation is the 'diet shift' amongst the Americans that contributes to this figure. It is expected that an increase in disease burden will be observed in coming years, especially in North America which has contributed a raise of 5\% prevalence, annually [5].

The demand of PPIs is directly proportional to the increasing prevalence, making it third most sold medication in US, annually making a $\$ 13$ billion market [6]. Another independent report from IMS Health stated a $\$ 6$ billion market in 2012 from a single PPI brand, Nexium [7]. The market dynamics are quite favorable for the pharmaceutical companies to invest in this pool for a lucrative future. It is possible that more licenses for production of PPIs will be issued internationally to counter the increasing 
prevalence of GERD. But are we sure that this huge market share is not blinding the adverse effects or that the companies are reluctant to share the post-market surveillance reports? The fact is that evidence based side effects of PPIs have yet been documented.

Despite its good safety profile, a recent statistical study published from Stanford University involving the data-mining of the previous consumers of PPIs have established an alarming situation for the patients. The study has stated PPIs causing myocardial infarction (MI) independently, a shocking statement for a drug which is used in high numbers and for nearly half a century [8]. How this study will be addressed is a big question for the boards of the healthcare professionals as well as by the regulatory authorities.

\section{Physiology, Drug Interactions and Side Effects}

PPIs inhibit $\mathrm{H}^{+} / \mathrm{K}^{+}$ATPase, which prevents the secretion of $\mathrm{H}+$, responsible for $\mathrm{HCl}$ in stomach. By inhibiting this channel, there is decreased acid formation, eventually the reflux will be devoid of acid. This will prevent from heartburning and adversity of the exaggerated physiological process [3]. So far, it is considered as one of the safest drug groups because the documented studies presenting adverse effects are not very representative for the populations. Although altering the pharmacodynamics of clopidogrel and hampering in some electrolyte physiology are a few commonly known effects. One important side effect is its inhibiting capacity of cytochrome P450 enzymes. Any drug involving this pathway must be used with extra caution. The interactions of PPIs with other chemical compounds are collected in Table 1 [9-17].

Table 1: Various mode of interactions and alterations by PPIs with minerals, electrolytes and drugs.

\begin{tabular}{|c|c|}
\hline Vitamin C [9] & Mode of Interaction and Adverse Effects with PPIs \\
\hline Calcium [10-12] & $\begin{array}{c}\text { Vitamin C is secreted in gastric juice. By lowering the acid secretion, } \\
\text { there is a fall of active anti-oxidant compound i.e. ascorbic acid. The } \\
\text { bioavailability of ingested vitamin C is also decreased. }\end{array}$ \\
\hline Vitamin B12 [13] & $\begin{array}{c}\text { Gastric acid facilitates the absorption of calcium, lowering bone mineral } \\
\text { density that can cause fractures. A known association of hip fractures } \\
\text { and PPI consumption is available. PPIs can inhibit the pumps in } \\
\text { osteoclast, increasing the bone density, fall in urinary calcium. Although } \\
\text { bone cell turnover can be decreased. }\end{array}$ \\
\hline Iron [15] & $\begin{array}{c}\text { B12-R complex is formed by gastric acid. PPIs inhibit this complex } \\
\text { formation, decreasing the available mineral. Megaloblastic anemia can } \\
\text { be caused by it. Another study negates an association of low B12 levels } \\
\text { with use of PPIs [14]. }\end{array}$ \\
\hline Clopidogrel & $\begin{array}{c}\text { Iron deficiency anemia with fall of other hematologic indices by chronic } \\
\text { use. Only one study proves it although with a limitation of less sample } \\
\text { size and other potential confounders. }\end{array}$ \\
\hline & $\begin{array}{c}\text { It is metabolized to active form by CYP2C19 and CYP3A4. PPIs, mainly } \\
\text { omeprazole and esmeprazole are considered potent inhibitors of these } \\
\text { P450 pathway coenzymes [16]. The reason that clopidogrel is not } \\
\text { available favoring thrombotic events. FDA is against the combined use of } \\
\text { both of these drugs [17]. }\end{array}$ \\
\hline
\end{tabular}

\section{Clopidogrel, MI and PPIs}

Coronary disease or MI constitutes the leading cause of death in western world and will keep on increasing in coming years [18]. Previously, the condition used to be diagnosed by electrocardiograms, which have almost now been replaced by cardiac biomarkers with Troponin I and T, the most specific markers to identify the disease. Troponin does not provide an accurate diagnosis but enables a comprehensive look into prognosis. With these advancements, better treatment algorithms have evolved in past years to prevent subsequent episodes of MI [19-21]. The American Heart Association devised an algorithm to treat this disease and its variants along with cerebrovascular accidents with clopidogrel, a pivotal medicine preventing thrombotic events. It is indicated in ST-elevated ischemia, stable or unstable angina and percutaneous coronary interventions $[22,23]$.
It has been proven that PPIs hamper the clopidogrel metabolism which reduces the bioavailability of active ingredient that provides anti-platelet function, promoting thrombi, eventually MI. Clopidogrel is an oral medication with main indication in central or peripheral vascular events. It works by inhibiting ADP receptors that are responsible for aggregation of the platelet clumping [24]. PPIs are inhibitors of hepatic cytochromes hindering in the normal anti-platelet physiology of clopidogrel. In 2009, after a clinical cohort study was released, a clear warning was issued by the US FDA suggesting PPIs should not be used with clopidogrel.

Fontes-Carvalho $\mathrm{R}$ [25] carried a cross over trial of clopidogrel users, first with omeprazole and after a washout period, pantoprazole. The efficacy of clopidogrel was maintained in the second trial, the drawn conclusions favored pantoprazole over omeprazole. A single dose of pantoprazole showed 
significant lowering of acid amongst the fast metabolizing genotype CYP2C19 [26]. A study carried by Siller-Matula [27] from Vienna on 300 patients, including coronary artery disease (CAD) and percutaneous coronary intervention (PCI) concluded that pantoprazole and esomeprazole are not associated with impaired response of clopidogrel based upon the platelet reactivity index. Some safer evidence about lansoprazole is available as well from Small DS, suggesting its non-interactive behavior with clopidogrel or prasugrel [28]. If PPIs are an absolute need, pantoprazole may be considered for use because of its minimal effects on CYP enzymes, unlike others in this group [29].

Amid safe and unsafe PPIs and mixed conclusions, a study comprising of an extensive cohort of PCI and ACS patient from 3 states in the US, with an extended timeline of 5 years, concluded that there is no evidence of PPI-clopidogrel interaction, or if evidence exists it is less than $20 \%$. The study can be objectionable but it has to be considered that the sample size of clopidogrel users is huge $(n=18,565)$ to establish this new side of debate [30]. Despite such favorable points for PPIs, an objection was raised by Potter [31] demanding the clarification of the developed score adjustment, cohort development and some non-compliance issues of the included sample units.

These studies have provided evidence that the whole group of PPIs cannot be discarded overnight for causing direct or indirect interaction with clopidogrel and the FDA needs to once again probe into the matter as revised version of the warning may be needed.

\section{Independent of Clopidogrel use amongst the PPI Users}

The association of PPI with myocardial infarction is not only related to interaction with Clopidogrel. Charlot et al. [32] conducted a large retrospective included aspirin treated patients, excluding Clopidogrel treated patients, and showed an increase of cardiovascular effects in patients treated with PPI when compared with patients treated with $\mathrm{H} 2$ receptor blocker. Charlot et al. [33] in a cohort study which included nationwide unselected population showed that PPI alone was associated with increase of myocardial infarctions; the authors concluded that the believed explanation for the correlation of PPI and Clopidogrel use with myocardial infarction is explained by the presence of confounders [33]. CREDO (Clopidogrel for the Reduction of Events during Observation) trial showed that patients treated with PPI, regardless if they received Clopidogrel or placebo, had an increase in cardiovascular events when compared to patients without PPI use [34]. Clopidogrel and the Optimization of Gastrointestinal Events Trial (COGNET) did not show any difference in rate of cardiovascular events in patients treated with or without PPI. Despite that the trial conflicted with results of previous studies, this trial was underpowered and resulted in a wide hazard ratio for cardiovascular events [35].

\section{Discussion}

Though we quoted a few studies which somehow correlate that MI is associated with PPI users whether they were clopidogrel users or not, we must consider that the facts established were either simple observations or drawn from patients already with multiple diseases. There are limitations to the documented knowledge and it must be remembered that we cannot neglect these observations. It is clear that safety of the drug requires long time post market surveillance. Nonetheless the chances of bias cannot be completely ignored. The observation of MI in those taking PPIs along with clopidogrel is understandable, but the studies suggesting an independent association is a query still to be answered. Either clinical trials or extensive cohorts can only be clinically and statistically relevant.

\section{References}

1. Forte JG, Lee HC (1977) Gastric adenosine triphosphatases: a review of their possible role in $\mathrm{HCl}$ secretion. Gastroenterology 73(4 Pt 2): 921926.

2. Lindberg P, Carlsson E (2006) Esomeprazole in the Framework of Proton-Pump Inhibitor Development. FISCHER: analogue-based drug discovery, pp. 81-113.

3. Zajac P, Holbrook A, Super M, Vogt M (2013) An overview: Current clinical guidelines for the evaluation, diagnosis, treatment, and management of dyspepsia. Osteopathic Family Physician 5(2): 79-85.

4. El-Serag H, Sweet S, Winchester C, Dent J (2013) Update on the epidemiology of gastro-oesophageal reflux disease: a systematic review. Gut 63(6): 871-880

5. El-Serag H (2007) Time Trends of Gastroesophageal Reflux Disease: A Systematic Review. Clin Gastroenterol Hepatol 5(1): 17-26.

6. Madanick R (2011) Proton pump inhibitor side effects and drug interactions: Much ado about nothing? Cleve Clin J Med 78(1): 39-49.

7. Bliss SJ (2015) Find the Best Proton Pump Inhibitors (PPIs). Health line.

8. Shah N, LePendu P, Bauer-Mehren A, Ghebremariam Y, Iyer SV, et al. (2015) Proton Pump Inhibitor Usage and the Risk of Myocardial Infarction in the General Population. PLoS One 10(6): e0124653.

9. McColl KE (2009) Effect of proton pump inhibitors on vitamins and iron. Am J Gastroenterol 104(Suppl 2): S5-S9.

10. Jefferies KC, Cipriano DJ, Forgac M (2008) Function structure and regulation of the vacuolar $(\mathrm{H}+)$-ATPases. Arch Biochem Biophys 476(1): 33-42.

11. Ngamruengphong S, Leontiadis GI, Radhi S, Dentino A, Nugent $\mathrm{K}$ (2011) Proton pump inhibitors and risk of fracture: a systematic review and meta-analysis of observational studies. Am J Gastroenterol 106(7): 1209-1218.

12. (2009) Do PPIs have long-term side effects? Harvard Health Latter.

13. Howden CW (2000) Vitamin B12 levels during prolonged treatment with proton pump inhibitors. J Clin Gastroenterol 30(1): 29-33.

14. denElzen WP, Groeneveld Y, de Ruijter W, Souverijn JH, le Cessie S, et al. (2008) Long-term use of proton pump inhibitors and vitamin B12 status in elderly individuals. Aliment Pharmacol Ther 27(6): 491-497.

15. Sarzynski E, Puttarajappa C, Xie Y, Grover M, Laird-Fick H (2011) Association between proton pump inhibitor use and anemia: a retrospective cohort study. Dig Dis Sci 56(8): 2349-2353. 
16. Kazui M, Nishiya Y, Ishizuka T, Hagihara K, Farid NA, et al. (2010) Identification of the human cytochrome P450 enzymes involved in the two oxidative steps in the bioactivation of clopidogrel to its pharmacologically active metabolite. Drug Metab Dispos 38(1): 92-99.

17. (2009) Early Communication about an Ongoing Safety Review of Clopidogrel Bisulfate (marketed as Plavix) and Omeprazole (marketed as Prilosec and Prilosec OTC). US Food \& Drug Administration.

18. Thom T, Haase N, Rosamond W, Howard VJ, Rumsfeld J, et al. (2006) Heart disease and stroke statistics--2006 update: a report from the American heart association statistics committee and stroke statistics subcommittee. Circulation 113(6): e85-e151.

19. Braunwald E, Antman EM, Beasley JW, Califf RM, Cheitlin MD, et al. (2000) ACC/AHA Guidelines for the Management of Patients With Unstable Angina and Non-ST-Segment Elevation Myocardial Infarction: Executive Summary and Recommendations : A Report of the American College of Cardiology/American Heart Association Task Force on Practice Guidelines (Committee on the Management of Patients With Unstable Angina). Circulation 102(10): 1193-1209.

20. Antman EM, Tanasijevic MJ, Thompson B, Schactman M, McCabe CH, et al. (1996) Cardiac-Specific Troponin I Levels to Predict the Risk of Mortality in Patients with Acute Coronary Syndromes. N Engl J Med 335(18): 1342-1349.

21. Ohman EM, Armstrong PW, Christenson RH, Granger CB, Katus HA, et al. (1996) Cardiac Troponin T Levels for Risk Stratification in Acute Myocardial Ischemia. N Engl J Med 335(18): 1333-1342.

22. O'Gara PT, Kushner FG, Ascheim DD, Casey DE, Chung MK, et al. (2013) 2013 ACCF/AHA Guideline for the Management of ST-Elevation Myocardial Infarction: Executive Summary. J Am Coll Cardiol 61(4): 485-510.

23. Jneid H, Anderson JL, Wright RS, Adams CD, Bridges CR, et al. (2013) 2012 ACCF/AHA Focused Update of the Guideline for the Management of Patients With Unstable Angina/Non-ST-Elevation Myocardial Infarction (Updating the 2007 Guideline and Replacing the 2011 Focused Update): A Report of the American College of Cardiology Foundation/American Heart Association Task Force on Practice Guidelines. Circulation 126(7): 875-910.

24. Liu Q Dang DS, Chen YF, Yan M, Shi GB, et al. (2015) The influence of omeprazole on platelet inhibition of clopidogrel in various CYP2C19 mutant alleles. Genet Test Mol Biomarkers 16(11): 1293-1297.

25. Fontes-Carvalho R, Albuquerque A, Araújo C, Pimentel-Nunes P, Ribeiro VG (2011) Omeprazole, but not pantoprazole, reduces the antiplatelet effect of clopidogrel: a randomized clinical crossover trial in patients after myocardial infarction evaluating the clopidogrel-PPIs drug interaction. Eur J Gastroenterol Hepatol 23(5): 396-404.

26. Hunfeld NG, Mathot RA, Touw DJ, van Schaik RH, Mulder PG, et al. (2008) Effect of CYP2C19*2 and *17 mutations on pharmacodynamics and kinetics of proton pump inhibitors in Caucasians. $\mathrm{Br} \mathrm{J}$ Clin Pharmacol 65(5): 752-760.

27. Siller-Matula JM, Spiel AO, Lang IM, Kreiner G, Christ G, et al. (2009) Effects of pantoprazole and esomeprazole on platelet inhibition by clopidogrel. Am Heart J 157(1): 148.e1-148.e5.

28. Small DS, Farid NA, Payne CD, Weerakkody GJ, Li YG, et al. (2008) Effects of the Proton Pump Inhibitor Lansoprazole on the Pharmacokinetics and Pharmacodynamics of Prasugrel and Clopidogrel. J Clin Pharmacol 48(4): 475-484

29. Drepper MD, Spahr L, Frossard JL (2012) Clopidogrel and proton pump inhibitors -where do we stand in 2012? World J Gastroenterol 18(18): 2161-2171.

30. Rassen JA, Choudhry NK, Avorn J, Schneeweiss S, et al. (2009) Cardiovascular outcomes and mortality in patients using clopidogrel with proton pump inhibitors after percutaneous coronary intervention or acute coronary syndrome. Circulation 120(23): 2322-2329.

31. Potter BJ, Le Lorier J (2010) Letter by Potter and Le Lorier regarding article, cardiovascular outcomes and mortality in patients using clopidogrel with proton pump inhibitors after percutaneous coronary intervention or acute coronary syndrome. Circulation 122(5): e414.

32. Charlot M, Grove EL, Hansen PR, Olesen JB, Ahlehoff O, et al. (2011) Proton pump inhibitor use and risk of adverse cardiovascular events in aspirin treated patients with first time myocardial infarction: nationwide propensity score matched study. BMJ 342: d2690.

33. Charlot M, Ahlehoff O, Norgaard ML, Jørgensen CH, Sørensen R, et al. (2010) Proton-pump inhibitors are associated with increased cardiovascular risk independent of clopidogrel use: a nationwide cohort study. Ann Intern Med 153(6): 378-386.

34. Dunn SP, Macaulay TE, Brennan DM, Campbell CL, Charnigo RJ, et al. (2008) Baseline proton pump inhibitor use is associated with increased cardiovascular events with and without the use of clopidogrel in the CREDO trial. Circulation 118: S815.

35. Bhatt DL, Cryer BL, Contant CF, Cohen M, Lanas A, et al. (2010) Clopidogrel with or without Omeprazole in Coronary Artery Disease. N Engl J Med 363(20): 1909-1917.

\section{Your next submission with Juniper Publishers} will reach you the below assets

- Quality Editorial service

- Swift Peer Review

- Reprints availability

- E-prints Service

- Manuscript Podcast for convenient understanding

- Global attainment for your research

- Manuscript accessibility in different formats

( Pdf, E-pub, Full Text, Audio)

- Unceasing customer service

Track the below URL for one-step submission https://juniperpublishers.com/online-submission.php 